\title{
TRADUÇÃO COMENTADA DO CONTO CINTA GRABADA DO ESCRITOR PARAGUAIO MARIO HALLEY MORA
}

\author{
COMMENTED TRANSLATION OF THE STORY CINTA GRABADA BY THE \\ PARAGUAYAN WRITER MARIO HALLEY MORA
}

\author{
TRADUCCIÓN COMENTADA EL CUENTO CINTA GRABADA DEL ESCRITOR \\ PARAGUAYO MARIO HALLEY MORA
}

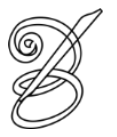 \\ Maria Liz BENITEZ ALMEIDA* \\ Universidade Federal do Rio Grande do Sul, Brasil
}

\begin{abstract}
Resumo: O texto apresenta a tradução comentada ao português do conto Cinta grabada do escritor paraguaio Mario Halley Mora. Temos como objetivo discorrer brevemente sobre as escolhas tradutórias com o intuito de problematizar, sob o viés da Sociolinguística, a diversidade dos sistemas linguísticos envolvidos no texto fonte: o espanhol e o guarani; assim como os recursos utilizados na língua de chegada: a variedade do português brasileiro. Segundo Rabadán (1991), é usual na literatura o uso de variedades diatópicas ou diastráticas na caracterização dos personagens. Observa-se que a literatura paraguaia está permeada de usos da língua guarani, seja no emprego de léxicos, seja na manifestação de sua influência na variedade do espanhol paraguaio. $\mathrm{O}$ autor, com o objetivo de retratar a realidade linguística do Paraguai, mobiliza, na fala de seu personagem, características da classe social menos escolarizada (dimensão diastrática). Desse modo, na tradução, consideramos o bilinguismo paraguaio multissecular, produto do contato entre o guarani e o espanhol, que gerou influências mútuas entre ambas as línguas envolvidas. Na variedade do espanhol paraguaio, é possível avistar não só influências lexicais do guarani (resultado mais evidente do contato), senão influências fonéticas e morfossintáticas. Tais características estão formuladas no conto e desafiam o trabalho do tradutor. A riqueza do conto não se restringe apenas à variedade recriada na fala do narrador. Os causos rememorados por ele apresentam ao leitor fatos marcantes na história paraguaia, como a Guerra da Tríplice Aliança e suas consequências sociais, bem como o papel da Igreja Católica na sociedade. O leitor também poderá acessar um breve glossário dos léxicos em guarani utilizados no conto, os quais foram mantidos na tradução a modo de aproximá-lo à realidade sociocultural do Paraguai. Além disso, apresentamos ao leitor de Língua Portuguesa um escritor pouco conhecido fora da ilha rodeada de terra, mas que teve uma vasta obra divulgada no Paraguai, pois, além de jornalista, foi contista, romancista e dramaturgo, tendo suas obras encenadas por todo o território até os dias atuais.
\end{abstract}

Palavras-chave: Tradução. Literatura paraguaia. Mario Halley Mora. Jopara. Sociolinguística.

Abstract: The text presents the commented translation into Portuguese of the short story Cinta grabada by the
Paraguayan writer Mario Halley Mora. The purpose of this article is to briefly discuss the translation choices
with the aim of problematizing the diversity of the linguistic systems involved in the source text: Spanish and
Guarani; as well as the resources used in the target language: the variety of Brazilian Portuguese. According to
Rabadan (1991), it is usual in the literature to use diatopic or diastratic varieties in the characterization of the
characters. It is observed that the Paraguayan literature is permeated by uses of the Guarani language, whether
in the use of lexicons or in the manifestation of its influence on the variety of Paraguayan Spanish. The author,
with the purpose of portraying the linguistic reality of Paraguay, mobilizes, in the speech of his character,
characteristics of the less educated social class (diastratic dimension). Thus, in the translation, we consider for
centuries Paraguayan bilingualism, product of the contact between the Guarani and the Spanish, that generated
mutual influences between both languages involved. In the variety of Paraguayan Spanish, it is possible to see not
only lexical influences of Guarani (the most evident result of contact), but also phonetic and morphosyntactic 
influences. Such characteristics are formulated in the short story and challenge the work of the translator. The richness of the story is not restricted to the variety re-created in the narrator's speech. The causes recalled by him present the reader with striking facts in Paraguayan history, such as the War of the Triple Alliance and its social consequences, as well as the role of the Catholic Church in society. The reader will also be able to access a brief glossary of the Guarani lexicons used in the short story, which have been kept in the translation in order to bring it closer to the socio-cultural reality of Paraguay. In addition, we presented the Portuguese-speaking reader with a little-known writer outside the island surrounded by land, but who had a vast work published in Paraguay, as a journalist, was a short storyteller, novelist and playwright, and his works were staged throughout the country territory to the present day.

Keywords: Translation. Paraguayan Literature. Mario Halley Mora. Jopara. Sociolinguistics.

Resumen: El texto presenta la traducción comentada al portugués del cuento Grabada del escritor paraguayo Cinta Mario Halley Mora. Tenemos como objetivo discurrir brevemente sobre las elecciones traductoras con el propósito de problematizar, bajo el sesgo de la Sociolingüística, la diversidad de los sistemas lingüísticos involucrados en el texto fuente: el español y el guaraní; así como los recursos utilizados en la lengua de destino: la variedad de portugués de brasileño. Según Rabadán (1991), es usual en la literatura el uso de variedades diatópicas o diastráticas en la caracterización de los personajes. Se observa que la literatura paraguaya está permeada de usos de la lengua guaraní, sea en el empleo de léxicos, sea en la manifestación de su influencia en la variedad del español paraguayo. El autor, con el objetivo de retratar la realidad lingüística del Paraguay, moviliza, en el habla de su personaje, características de la clase social menos escolarizada (dimensión diastrática). De ese modo, en la traducción, consideramos el bilingüismo paraguayo multisecular, producto del contacto entre el guaraní y el español, que generó influencias mutuas entre ambas lenguas involucradas. En la variedad del español paraguayo, es posible avistar no sólo influencias lexicales del guaraní (resultado más evidente del contacto), sino influencias fonéticas y morfosintácticas. Tales características están formuladas en el cuento y desafían el trabajo del traductor. La riqueza del cuento no se restringe sólo a la variedad recreada en el habla del narrador. Los casos rememorados por él presentan al lector hechos destacados en la historia paraguaya, como la Guerra de la Triple Alianza y sus consecuencias sociales, así como el papel de la Iglesia

194 Católica en la sociedad. El lector también podrá acceder a un breve glosario de los léxicos en guaraní utilizados en el cuento, los cuales fueron mantenidos en la traducción a modo de acercarlo a la realidad sociocultural del Paraguay. Además, se presentará al portugués un escritor poco conocido fuera de la isla rodeada de tierra, pero con una vasta obra publicada en Paraguay, porque además de periodista, fue cuentista, novelista y dramaturgo, y sus obras han sido exhibidas largo del territorio hasta los días actuales.

Palabras-clave: Traducción. Literatura paraguaya. Mario Halley Mora. Jopara. Sociolingüística.

RECEBIDO EM: 10/05/2019

ACEITO EM: 23/08/2019

PUBLICADO EM: 10/2019

BENITEZ ALMEIDA, Maria Liz. Tradução comentada do conto Cinta grabada do escritor paraguaio Mario Halley Mora. Belas Infiéis, Brasília, v. 8, n. 4, p. 193-206, 2019. 


\section{Por que traduzir Mario Halley Mora ao português?}

ario Halley Mora (1926-2003), embora pouco conhecido no Brasil, é autor de uma
vasta obra literária e de uma sólida carreira de produção cultural. Além de
trabalhar como jornalista, publicou obras teatrais, romances, poemas, livros de contos, escreveu roteiro de filmes e quadrinhos, além de ser o autor da letra de uma zarzuela em jopara (guarani-espanhol) (MÉNDEZ-FAITH, 2001, p. 139).

Em sua obra teatral explorou o tema da hipocrisia da classe média (CORTÉS; BARREA-MARLYS, 2003, p. 347). Seus romances modernizam as técnicas narrativas e exploram a realidade urbana da cidade de Assunção, com um enfoque em temas e personagens femininos. Também foi o introdutor do micro conto no Paraguai (PEIRÓ, 2001, p. 439).

Em parte, é possível verificar certa resistência a seu trabalho literário que se dá em função de sua atividade jornalística durante o período ditatorial de Alfredo Stroessner (19541989). Roa Bastos chegou a denominar a literatura produzida no Paraguai durante esse período como "ausente", classificando a existência de dois exílios, o exterior, no qual ele mesmo escrevia e o exílio interior, no qual se enquadrariam os escritores que permaneceram no país (BENISZ, 2013).

Não obstante, como registra Victorio Suárez (2015, p. 217), "si bien muchos han cuestionado su labor periodística durante la dictadura, nadie puede negar que se trata de una de las voces mejor dotadas de la literatura paraguaya". Alijados do contexto político da escritura de suas obras, é possível atualmente lançar novos olhares sobre o valor literário de suas produções, que justificam sua tradução e sua submissão ao leitor de Língua Portuguesa.

\section{Contextualização do conto e das obras de Mario Halley Mora}

Cinta Grabada faz parte da obra Cuentos, microcuentos y anticuentos, publicada em 1987, pela editora El Lector. Nela, além dos contos, o autor introduz na literatura paraguaia os gêneros microconto e anticonto. $\mathrm{O}$ microconto consiste em narrar histórias no menor número de palavras possíveis. $\mathrm{O}$ anticonto, por sua vez, é um gênero que sai do relato tradicional, cujas situações apresentam soluções absurdas (BARCO, 2002).

As análises das características narrativas do autor e de seu legado, de um modo geral, são escassas, o que vai ao encontro da afirmação feita na primeira seção deste artigo. Os estudos que buscam apresentar uma historiografia não avançam de resumos biográficos e uma lista das obras do autor (SUÁREZ, 2015); outras, mais atuais, sequer o mencionam (DELGADO, 2012) ${ }^{1}$. Barco (2002) observa que as obras do autor recriam temática de cunho social e popular, 
tendo uma tendência realista e o uso de falas que caracterizam os paraguaios com fortes inserções do guarani. Além disso, Halley Mora inicia a narrativa citadina, cujos ambientes são a cidade de Asunción:

[...] no sólo por haber sido el primer creador de la novela de Asunción, sobre todo porque todas sus novelas se localizan en la ciudad y su incursión en este tipo de narrativa no ha sido circunstancial y aislada, sino por la profundidad y la sensibilidad con que trata los problemas humanos y su papel innovador en el cuento paraguayo con sus microcuentos y anticuentos (BARCO, 2002, p. 1471).

Seus personagens oscilam da classe baixa à classe alta da sociedade paraguaia. Problematiza aspectos sociais e econômicos como o êxodo rural, que ocorre no país a partir da década de 1980. Essa temática também é explorada no romance Los hombres de Celina, publicado em 1981.

Desse modo, a escolha de Cinta Grabada para tradução decorre da condensação de características sociais, históricas e linguísticas. O conto é apresentado sob a forma de transcrição de uma conversa gravada. Durante o desenrolar dessa conversa, o narrador conta histórias de seu vilarejo que ficarão registradas na fita gravada. A narrativa, que busca seguir a cadência de uma conversa informal, resulta em uma miscelânea de menções a eventos que marcaram a sociedade paraguaia, tais como a Guerra da Tríplice Aliança (1864-1870), a Guerra do Chaco (1932-1935) e a Revolução de 1947, o que ajuda a compreender o tempo em que se passam as histórias contadas e permitem vislumbrar peculiaridades das relações sociais e históricas do Paraguai.

Um dos primeiros elementos que aparecem no conto é o uso do lenço partidário, que era a forma pela qual, publicamente, os indivíduos manifestavam-se como integrantes do Partido Liberal ou Colorado. O bipartidarismo é característica tão marcante que Morínigo (2002) propõe que, no campo político, a história do Paraguai pode ser lida como a história de dois partidos. O narrador do conto, após ter lutado em uma das guerras e embora se tenha em algum momento identificado como membro partidário, nega-se a participar do conflito interpartidário que resultou na guerra civil de 1947.

Ainda como consequência da histórica bélica do Paraguai, ao narrar a história de Aparicia Peña, refere que o pai da moça era "homem era um desses que, depois da Guerra Grande, percorriam o interior semeando filhos”. Guerra Grande ou Guerra da Tríplice Aliança é a forma como os paraguaios nomeiam a Guerra do Paraguai. O fato é que, devido ao conflito, a população masculina foi dizimada (ARECES, 2011, p. 193), fazendo com que se tornasse 
aceitável, mesmo em uma sociedade conservadora, relações efêmeras e extraconjugais, para reerguer o país. O protagonismo feminino na reconstrução econômica e social do país, no entanto, não resultou em emancipação do domínio masculino (POTTHAST, 2011, p. 325) , o que se nota no comportamento do personagem Celso.

Por fim, a narrativa envolve questões ligadas à religiosidade paraguaia, vinculada principalmente à tradição da Igreja Católica, que remonta à chegada dos jesuítas.

\section{Escolhas tradutórias pelo viés da diversidade linguística}

Como salienta Garcez (1999), no processo tradutório, ao envolver linguagem, é inescapável tratar de diversidade, qualidade intrínseca à língua, visto que, como explica Faraco, “[...] a língua é uma realidade heterogênea, multifacetada e que as mudanças emergem dessa heterogeneidade, embora de nem todo fato heterogêneo resulte necessariamente em mudança" (FARACO, 1998, p. 13). Na literatura é usual o emprego de variedades para caracterização dos personagens, o que apresenta dificuldades para a tradução, segundo Rabadán (1991, p. 112), pois “[...] la configuración geográfica y por otro lado dialectal, de dos países y dos lenguas no son equiparables, como tampoco lo son las relaciones intrasistémicas que se establecen entre ellos". Surgem, desse modo, questionamentos sobre como traduzir a caracterização da classe social menos escolarizada, cuja variedade é resultado do contato com uma língua indígena. Além disso, coloca-se o desafio de lidar com léxicos utilizados pelo personagem em guarani.

Nesse sentido, ao ter como língua fonte o sistema linguístico do espanhol paraguaio, deparamo-nos ante a realidade de que esta é resultado do contato de vários séculos com o guarani. Assim, temos no Paraguai uma realidade linguística bastante peculiar, o convívio de duas línguas geneticamente diferentes que foram se influenciando mutuamente.

Como resultado desse convívio linguístico temos o jopara, designação utilizada para descrever o estágio mais avançado do contato. Kallfell (2016) assinala que as influências do guarani não se restringem aos campos fonético e léxico, mas também alcançam o campo morfossintático. Fatores como competência linguística, classe social e contextos situacionais condicionam o uso do jopara. No mesmo sentido:

no se pueden cerrar los ojos ante el hecho de que la realidad lingüística del Paraguay está caracterizada por la profunda compenetración léxica y sintáctica del guaraní con el español paraguayo. El discurso jopara, cuya estructura es esencialmente guaraní pero que integra un alto porcentaje de vocabulario español (cf. LUSTIG, 1996), sale - muy a pesar de algunos maestros- de la boca de todos (LUSTIG, 2002). 
A literatura paraguaia também é permeada por esse fenômeno, tanto é assim que Renée Ferrer (2011, p. 2) adverte: “el bilinguismo hispanoguarani condicionó casi toda la producción de los últimos cincuenta años, llevando a los narradores a la búsqueda de soluciones diversas en su esfuerzo por integrar la lengua soterrada al discurso narrativo en castellano". Ao autor Mario Halley Mora não escapa essa realidade linguística, cuja representação é realizada por meio da fala do narrador. Nesse conto específico, Halley Mora, por meio do título, faz com que o leitor perceba a narrativa como um registro encontrado em uma fita cassete. Por isso, busca representar a variedade do falante paraguaio sem as amarras do texto escrito, apresentando também cortes que indicam que a gravação se teria dado diante de um interlocutor.

Devido ao espaço, ateremo-nos, principalmente, aos aspectos linguísticos e às escolhas tradutórias. Para aproximar o texto da oralidade na língua de chegada, escolhemos a variedade do português brasileiro falado. É importante salientar que no conto apenas é perceptível a dimensão diastrática, sem elementos que permitam identificar a dimensão diatópica. Portanto, buscamos equivalências no português que aproximem à fala da classe menos escolarizada. Halley Mora usa, por exemplo, "güeno" para fazer a representação de uma pronúncia mais interiorana da palavra "bueno". Por isso, adotamos "bão". Ao se referir ao interlocutor pelo pronome de tratamento formal "usted", a fala é representada com a queda do "d" final. Aqui, embora não possamos atribuir a queda da consoante final ao guarani, é importante salientar que ele não possui fonemas consonânticos finais à diferença do espanhol (CERNO, 2011). Entretanto, a fala interiorana e da classe social menos escolarizada tem fortes influências do guarani, cujas características fonéticas, lexicais e morfossintáticas se transferem ao espanhol paraguaio. Ainda buscando formalidade, o narrador, por vezes, ao interpelar o interlocutor usa o pronome de tratamento "don". Para ambas as expressões, optamos por "sinhô".

Além desses exemplos de adaptação léxica, buscamos manter a concordância verbal e nominal que constam na narrativa, pois é possível representar esse fenômeno na língua de chegada, que caracteriza o falante da classe menos escolarizada. Essa concordância que desvia da norma padrão da Língua Espanhola no texto fonte também é característica da classe menos escolarizada, que tem como língua predominante o guarani, cuja pluralização não está marcada pela flexão como nas línguas românicas, e sim pelas partículas: kuéra/nguéra.

O guarani, originalmente não possui artigos definidos, no entanto, no convívio multissecular com o espanhol acabou adotando as formas $l a$ e $l o^{2}$. Esses artigos adquirem novos usos no guarani, que regressam ao espanhol paraguaio por meio de um empréstimo reversivo. Essa característica se registra, por exemplo, na fala do narrador: "que lo gringo andan". Para 
essa construção na língua de chegada, encontramos como solução a estrutura "que os gringo anda", característica da língua falada. Nos demais casos semelhantes, em sintagmas nominais e verbais, buscamos manter essa estrutura como diretriz tradutória.

Do mesmo modo, optamos por substituir os pronomes oblíquos utilizados no texto fonte pelos pronomes do caso reto, característico da fala no português brasileiro. Assim, no excerto "qué quiere que le diga, carâ̂", onde há o uso do pronome oblíquo, optamos pela elisão: "que cê qué que eu diga, karai". No mesmo sentido "que le mandó salir de su casa” foi traduzido por "que mandou ela sair de casa". Esse procedimento estendeu-se às demais ocorrências.

Foram preservadas, no texto, as palavras em guarani, pois consideramos que é uma forma de provocar o leitor a se deparar com a alteridade (ANTUNES, 2019) e refletir sobre a diversidade linguística do Paraguai, que perpassa fronteiras e vai ao encontro da própria realidade do leitor brasileiro, tendo em consideração a relação histórica que também o Brasil guarda com suas línguas indígenas. Ademais, não passam de 12 as palavras vertidas em guarani.

Levando em conta que a grafia do guarani passou por diferentes processos de sistematização desde o primeiro registro feito pelos jesuítas, optamos por adequar as palavras à ortografia contemporânea, com base no dicionário Ñe'êryru (CANESE; ALCARAZ, 2015). Para melhor explicitar isso, incluímos um breve glossário com a ortografia utilizada no original e sua correspondente atualizada.

Dentre as palavras em guarani presentes no texto, há duas cujos aspectos etimológicos são importantes de destacar: karai e pa'i.

Karai, de origem tupi-guarani carrega em si as relações históricas entre indígenas e colonizadores, principalmente se a olhamos pelo viés da variação diacrônica. O sentido préhispânico da palavra é xamã, que era o líder religioso da tribo. Antonio Ruiz de Montoya, no Tesoro de la lengua guaraní (2011 [1939]), registra para essa palavra os sentidos de astuto e manhoso. Os indígenas passaram a designar os conquistadores com essa palavra no sentido da perspectiva jesuítica, também os sentidos de cristão, europeu e não indígena (THUN; CERNO; OBERMEIER, 2015). Por fim, se registram os sentidos de "senhor" na alocução cortês, sendo karai para o senhor e kuñakarai para a senhora, usos que se conservam no guarani paraguaio e é o sentido utilizado pelo autor no conto.

Processo semelhante deu-se com o vocábulo $p a^{\prime} i$. Originalmente, a palavra era vinculada ao contexto místico da religião aborígene, significando feiticeiro. Novamente, Antonio Ruiz de Montoya, em seu Tesoro de la lengua guaraní, ressignifica a expressão para fazê-la designar sacerdotes católicos (CHAMORRO, 2007, p. 236). 
Tecidas essas considerações iniciais, submetemos ao leitor os resultados do exercício tradutório e um glossário como os 11 termos em guarani que aparecem no texto.

Quadro 1 - Glossário

\begin{tabular}{|l|l|l|}
\hline Guarani atual & Redação do conto & Significado \\
\hline Kamba & Camba & Negro \\
\hline Karai & Caraí, cara-í & Homem, senhor \\
\hline Kuñataĩ & Cuñataí & Moça \\
\hline Guasu & Guazú & Grande \\
\hline Mitãkuña & Mita-cuña & Donzela, jovem, virgem \\
\hline Mitã'i & Mitaí & Menino \\
\hline Mitãrusu & Mita-ruzú & Rapaz, jovem \\
\hline Nandejára & Nandeyara & $\begin{array}{l}\text { Deus; Nosso Senhor (ñande- } \\
\text { nosso; jára - dono) }\end{array}$ \\
\hline Pa'i & Paí, pa-í & Padre, sacerdote \\
\hline Pirón kyra, pirõ kyra & Pirón-kyrá & $\begin{array}{l}\text { Comida típica paraguaia } \\
\text { semelhante à polenta }\end{array}$ \\
\hline Typói & Typo'í & Blusa típica paraguaia. \\
\hline
\end{tabular}

Elaboração: a autora

\section{Tradução}

\section{Fita Gravada}

- Eu não sou bão para contar causo e histórias, sinhô...

E mais ainda, quando falo castelhano parece que vou arrastando a palavra, meio a reboque do guarani que tenho em minha cabeça.

... Sim, é verdade que faz tempo que eu era professor de escola, mas isso era antes, quando pra ser professor não precisava ser mais estudado, só menos ignorante que o próximo...

... além disso, esse seu aparelhinho me deixa um pouco nervoso, sinhô, porque parece coisa de pajé.

Sim, já sei que veio por aqui um gringo louco que andava pelo mato apontando a coisa em direção ao canto do passarinho. E o canto ficava enrolado ali nessa fita. Igualzinho ao verdadeiro. Parece até, sinhô, que os gringo anda tão amontado por sua terra, que não há lugar pros pássaro. E então enlata e levam nessa fita os ruído do mato, como o leite que trazia o gringo que te digo que era uma coisa seca, mas colocava água e saia leite de a vera, e repartia pros mita' $i$ que vinha da escola...

... meio que me dá medo que o que sai de minha boca fique enrolado ali, sinhô. Parece uma pajelança, digo. Me parece que o bom Ñandejara quer que o que o próximo diz fique apenas no coração alheio, e se fica de fora um restinho, que leve o vento. Mas nesse seu carretel fica tudo, até um pedaço de eu mesmo porque é verdade que sou um velho já bem enrugado, sinhô, mas eu também sou minha memória e meu agora. 
- ... sou de 904. Bastante velho já, ou seja, que vim quando o Partido Colorado caiu do poder. Lá por 22, já brigava em Ca'i Puente, com meu lenço no pescoço. Muita gente morreu ali, karai. Me fui no Chaco em 32, com uniforme e sem lenço. Não quero nem contar isso.

Os home moreno e baixinho vinha e se metia no mato, a brigar com nós, mas era gente que vinha da montanha de pura pedra, e não conhecia o mato que é sempre traiçoeiro. Alguns deles morria de sede, porque nós se posicionava no poço de água e defendia como se fosse a teta de nossa terra. Costumo sonhar que estou outra vez ali, na trincheira, fazendo sentinela da guarita, ouvindo toda a noite a lamentação de algum boliviano perdido pelo mato:

“Aguinha, paraguainho!", gritava, mas não tinha nada pra fazer e era melhor deixar que morresse, e que não aconteça o que aconteceu ao Cabo Lesme, que se fez de cristão e deu água a um boliviano que estava sedento como um sorvedouro, e o homem tomou sua água e ainda por cima meteu-lhe uma bala na barriga de Lesme, em puro descuido, daí. Depois, na Revolução de 47 eu já não estava mais pra briga, e sabia que na guerra tem mais sofrimento que vantagem. Então só disse que não quando vieram pra me recrutar. Me bateram com relho até minha carne dizer chega, mas não era eu, mas minha carne, e caí meio morto e sem sentir mais nada. Me maltrataram muito, mesmo assim não fui. Sabia o que era a Revolução, pior que com os boliviano porque a gente pode matar um parente sem saber nada, e quando a pessoa sabe disso, o coração desbota, igualzinho que meu lenço velho de 22. E então eu não fui...

... que cê qué que eu diga, karai. O senhor me paga pra que lhe diga causos e histórias. Eu sou um causo. Um causo longo. E não tenho a culpa de que minha vida venha caminhando por cima de pelejas e sofrimentos. A gente vive como manda Nosso Senhor ou a política, e quem sou eu para remar contra a maré. As coisa são como são e tem que aguentar, se acomodar e andar como os outro quer, com a esperança de sair vivo ou com medo de ficar morto. É desse jeito, senhor. ... me lembro de muita coisa, mas custa um pouco botar tudo pra fora. E além disso, me parece um pouco forçado ficar falando do que aconteceu com uma pessoa que já não está mais. É como usar a palavra pra desenterrar o finado.

- ... isso diz o sinhô, que vem da Capital, e porque não tem os ano que eu tenho. A morte é o fim natural, diz o sinhô. Isso eu sei bem, mas aqui é outra coisa. Olhe um pouco o vale, parece pouca coisa. Olhe, o caminho de terra, que vem não sei de onde, parece que quer se agarrar um pouquinho a nosso povoado, mas vai seguindo até longe, cortando um monte que já não me alembro e uns banhado que não acaba mais. Parece pouca coisa o vale, sinhô, mas tem gente que não pensa como o sinhô, com todo respeito. Nós sabemo aqui que a morte não é o fim natural, mas que é parte da vida. É assim. Se deita com as muié e anda escondida debaixo do poncho dos forasteiros. A morte, como o caminho, se hospeda de noite no povoado, e de dia segue a jornada, para vir outra vez de noite. Vai e vem, e para que não se perca ponteia a borda do caminho com a cruzinha de alguém que se descuidou demais, e ficou finado ali mesmo para seu azar...

... é como se a morte vivesse com nós. E de tanto costume fica amiga, se olha pra ela um pouco de revés, mas amiga. E se eu digo que algumas vez se sente mãe, $c \hat{e}$ não vai acreditar. Sim, senhor, se sente mãe e leva um mitã' $i$, enrolado em seu manto negro. Um anjinho pro céu, sinhô. Por isso no velório do anjinho as muié chora e os home traz a arpa e a guitarra e entorna a noite toda. Assim é o vale, karai guasu... Buscamo em nosso sofrimento um motivo de violão pros home e de alegria pro céu. Pelo menos... 
-... e já que falamo disso, karai, agora me alembro de Aparicia Peña, que era a mais linda kuñataĩ do vale. Era linda e decente até não mais poder, e disso dou fé eu mesmo porque naquele tempo eu era moço como ela, e me entreverava um pouco também com os abobado que saíam da sesta para buscar pegadas de seu pé na areia, para recolher um punhadinho e fazer um escapulário que, enquanto se tem debaixo da camisa, obriga a moça a pensar na gente.

Vivia com sua mãe, sozinha, ao lado de um rancho que ainda se vê lá pelas beira da Ilha Guazú. De seu pai ninguém tinha nem notícia, ainda que me lembro que a velha do vale, diziam, que o home era um desses que, depois da Guerra Grande, percorria o interior semeando filhos.

- ... e não me ponha essa cara, sinhô. Era desse jeito, tô te falando.

A guerra terminou com os home e o povo, e vilarejo como este eram todo de muié. Então vinha os home, vinha de longe e ia pra longe, mas quando ficava um dia apenas, deixava um filho e levava suas provisão e já partia. Disso agora não se fala muito, como se o silêncio pudesse borrar o pecado, mas eu acho que pecado por pecado, pecado mais grande fazia a muié que não emprenhava, nem que seja para ter alguém para pôr o nome da gente da família que morreu na Guerra. Assim nasceu Aparicia Peña. Peña por parte de sua mãe e nada mais...

A kuñataĩ? Bão, era bonita pra mais de metro. Já não me lembro de como era sua cara, mas quando penso nela, ainda me despreguiça aqui no coração a brasinha que ainda me resta de meus tempo de mitãrusu.

Os domingo, quando ela ia à missa do vilarejo, sabia levar como ninguém seu rosário de coral 202 e filigrana sobre seu typói engomado, e seu brinco de três pedra e seu anel entrelaçado como só a gente de antes sabia fazer lá por Luque. Ela mostrava com orgulho essa prenda, que até agora não sei como sua mãe salvou dos kamba de dom Pedro II, que padecendo deve estar no Purgatório como dizia minha mãe, e fazia o sinal da cruz para tirar a sujeira da boca e da cabeça. Ela já estava naquela época de casar, e mais ainda porque era linda. E começou a namorar ela o filho de Seu Calaíto Florentín, ou seja, Celso, que era um rapaz decidido e trabalhador, sem mais vício que seu galo de rinha, que ele sabia adestrar para que sempre ganhasse honradamente, ou seja sem veneno na espora.

- ... por aquele tempo, tinha recém chegado um padrezinho italiano pa ’ $i$ Jovani; que com as própria mão arrumou a igreja do vilarejo que caía aos pedaços e andava louco querendo aprender um pouco de guarani, com certeza que para entender-se com as pessoas, o coitado. $P a ’ i$ Jovani, além de ser $p a ' i$, segundo diziam, escrevia livros. Não sei de que tipo, mas perguntava muito de tudo, e sempre estava anotando alguma coisa em seu caderninho que sempre carregava na borso da sua batina. E por aí o pa'i Jovani, conheceu a mãe de Aparicia Peña, que segundo era sabido, era fillha de uma família de categoria de Ybytimi, que ficou só e desamparada pela guerra, e o $p a{ }^{\prime} i$ visitava ela e não paravam de conversar e de lembrar e de anotar no caderninho, e só quando começava a ser noite, o pa ’ Iovani partia...

Bão. As coisa era assim, a Aparicia, que já estava completamente noiva de Celso, começou a ter barriga grande. Tô te falando, sinhô, se avultava a barriga da menina como se carregasse um mitã' $i$. Celso, com a faca na cintura, andava louco perguntando pelo nome do desgraçado que fez filho em sua namorada. Mas ninguém sabia dar notícia, nem ela mesma, que jurava por todos os santo que era mitãkuña ainda. Mas ninguém podia acreditar nisso olhado sua barriga. Nem sua mãe, que mandou ela sair de casa, diante de toda a vizinhança de nosso vilarejo. 
- Me lembro bem desse dia. Ela gritava que era inocente, e sua mãe que colocava ela pra fora, chorando ela também, com certeza que de tristeza por sua filha e também pelo orgulho ferido. A Aparicia pegou estrada. E a vizinhança dizia: "Agora que não tem casa, com certeza tem que ir pedir proteção pro home que prejudicou ela", e seguiram ela em bando pelo caminho, como os cachorro que seguem os boi que vão pro abatedouro. Ela foi direto à Igreja. E então as pessoa se olhava, fazia o sinal da cruz e dizia: "Foi o pa'i Jovani". E além disso, todos começava a calcular a barbaridade de tempo do tempo que o pa'i passava na casa da Aparicia.

... não faltou dedo-duro que foi correndo levar a notícia a Celso. E quando era tardezinha, viuse Celso que ia cruzando pela pracinha da Igreja, arrastando a sua velha mãe que se pendurava em sua roupa e implorava que não fizesse isso que ia fazer. Então ele empurrou sua mãe e seguiu seu caminho. E a velha ficou ali jogada e arrancando cabelo com a mão e gritando que quem mata um pa'i está condenado a sete eternidade no inferno do Demônio. Celso chegou na igreja e chamou o pa' $i$, e com a faca na mão se parecia com um de seus famosos galos de rinha, tremendo todo de vontade de matar. $P a{ }^{\prime} i$ Jovani saiu e caminhou em direção a Celso, com os braço aberto, não sei se para mostrar que estava desarmado, ou para ser uma cruz viva para apagar a maldade de Celso. Mas de nada valeu ao pa'i Jovani seu braço aberto em cruz, a não ser para acomodar melhor seu coração para receber a punhalada. O pa 'i caiu no chão, e Celso, gritando como louco que era, correu e se meteu no mato, - o encontraram um mês despois. Mas nunca se saberá se morreu de sua própria mão, ou de arrependimento, porque quando encontraram ele, estava quase todo comido pelas formiga.

- Pa'i Jovani não morreu em seguida, e sete dia passou em agonia. Veio o Bispo de Villarica para ver ele, e trouxe um doutor suíço que andava pela Cordilheira de Ybyturuzú anotando os nome da planta do mato. Mas pa'i Jovani morreu mesmo assim.

A noite que morreu o $p a$ ' $i$ Jovani, encontraram a Aparicia morta por sua própria mão pendurada na maior viga da sacristia.

- Muito tempo mais ficou o bispo e o doutor.

Chamava as pessoas na Igreja e perguntava e anotava tudo. Sempre assim, sinhô, e depois, um domingo fez missa, e falou às pessoas. O pa'i Jovani era inocente - disse o Bispo. Também Aparicia, porque o doutor revisou seu corpo que já era finado e ali não encontrou um mitã' $i$, mas uma enfermidade que não me lembro o nome, e é um tumor com uma bolsa de água que cresce na barriga, e parece coisa de muié que tá prenha...

- Como lhe digo, karai, a morte e a vida são tão juntinhas que parece que caminha sobre os mesmo pé.

É assim desde sempre. O sinhô diz que a morte é o fim. Com certeza, mas também a morte é o começo e o meio, tudo junto de uma vez. Ninguém não quer nascer para morrer, mas desde que uma pessoa é parida, o anjo da guarda já vem de luto, por via das dúvidas. A morte está em tudo, sinhô. Na espora do galo e no coração inocente que guarda seu amor sob o typói. Galopa sobre o cavalo do caudilho e forma fila entre as pessoas no dia de votação. Nunca dorme, porque sempre está alerta e te surpreende tão logo a cachaça te sobe na cabeça, ou o pé teimoso pisa a borda do poncho do semelhante. A morte sempre ronda pertinho da gente, como cachorro que espera uma sobra da vianda da vida, ou se não como forasteiro encrenqueiro que chega num baile e pede para dançar uma polka partidária, que é a polka da morte, porque põe medo no coração dos músico e afia a faca dos inimigo... 
- E assim é, karai. Eu sei outro causo deste vale, se quiser me ouvir. Mas se já está bem, vou para meu rancho, e se o sinhô é generoso como me disse, me dá o que me deve, que está me fazendo falta um pouco de erva para o mate e alguma farinha para o pirón kyrá...

\section{Considerações finais}

Nossa proposta teve como objetivo principal apresentar ao leitor brasileiro a tradução comentada do conto Cinta grabada do escritor paraguaio Mario Halley Mora. De modo sintético, é possível perceber a relevância desse autor e de sua obra - em especial a aqui traduzida - em três aspectos: i) histórico, ii) literário e iii) sociolinguístico.

Do ponto de vista histórico, o autor foi um profícuo escritor no Paraguai, com diversas obras publicadas, ensaiadas e exibidas pelo país. Sua atuação como escritor, dramaturgo, jornalista e diretor de redação deixaram suas impressões digitais na cena cultural paraguaia de sua época.

Sob o aspecto literário, apesar da relevância histórica no Paraguai, são escassos os trabalhos sobre sua obra no Brasil. Com o intuito de contextualizar as obras do autor na literatura paraguaia, recorremos às escassas fontes, razão pela qual discussões referentes ao estilo literário de Halley Mora foram tratados de forma breve, desafiando o aprofundamento de novas investigações.

Por fim, sob o enfoque sociolinguístico, o conto traduzido traz a possibilidade de reflexão sobre a variedade do espanhol paraguaio, com influxos do guarani, cujas particularidades acentuam-se na fala da classe menos escolarizada, fizemos o esforço de recriar algumas características representadas no conto. Possibilita-se, assim, ao leitor de Língua Portuguesa um primeiro contato o com sistema linguístico do guarani e sua relação com o espanhol paraguaio - variedade recriada pelo autor no conto.

Cientes da necessidade da complexidade do tema e da incompletude da abordagem aqui adotada, submetemos esta versão ao crivo do leitor de Língua Portuguesa.

\section{REFERÊNCIAS}

ANTUNES, Leonardo. Profissionais qualificam de livros no País. Jornal do Comércio, 2019. Disponível em: https://www.jornaldocomercio.com/_conteudo/cultura/2019/02/668718traducao-literaria.html?fbclid=IwAR2q58G1EYh-dVdlRlwCJsJhH6lhFvzOiJDVxQf5E2rZ17UYsf_5o4RZkU. Acesso em: 4 out. 2019.

ARECES, Nidia R. De la Independencia a la Guera de la Triple Alianza. In: TELESCA, Ignacio. Historia del Paraguay. 3. ed. Asunción: Santillana, 2011. p. 149-197. 
BARCO, José Vicente Peiró. Literatura y sociedad. La narrativa paraguaya actual (19801995). Alicante: Biblioteca Virtual Miguel de Cervantes (TESE), 2002.

BENISZ, Carla. Dos versiones de Judas. Acerca de dos novelas del exilio: Respiración artificial de Ricardo Piglia y El Fiscal de Augusto Roa Bastos. Revista Paraguay desde las Ciencias Sociales, Buenos Aires, v. 2, p. 45-64, 2013. Disponível em:

https://publicaciones.sociales.uba.ar/index.php/revistaparaguay/article/view/1730. Acesso em: 4 out. 2019.

CANESE, Natalia Krivoshein de.; ALCARAZ, Feliciano Acosta. Ñe'eryru. Asunción: Universidad Católica de Asunción, 2015.

CERNO, Leonardo. Descripción fonológica y morfosintáctica de una variedad de la lengua guaraní hablada en la provincia de Corrientes (Argentina). 2011. Tese (Doctorado) - Facultad de Humanidades y Artes, Universidad Nacional de Rosario, Rosario, Argentina.

CHAMORRO, Graciela. Cuerpo Social: Historia y Etnografia de la Organización Social en los Pueblos Guarani. v. II. Asunción: Tiempo de Historia - FONDEC, 2007.

CORTÉS, Eladio; BARREA-MARLYS, Mirta. Encyclopedia of Latin American Theater. 1. ed. Westport: Greenwood Press, 2003.

DELGADO, Suzy. Nombres Capitales de la Literatura Paraguaya: compilación y selección. Asunción: Servilibro, 2012.

FARACO, Carlos A. Linguística Histórica. São Paulo: Ática, 1998.

FERRER, Renée. Narrativa paraguaya actual : dos vertientes. Biblioteca Virtual Miguel de Cervantes, Biblioteca Virtual Miguel de Cervantes, [2001] 2011. Disponível em: http://www.cervantesvirtual.com/obra/narrativa-paraguaya-actual-dos-vertientes--0/. Acesso em: 4 out. 2019.

GARCEZ, Pedro M. Diversidade linguística: considerações para a tradução. Trabalhos em Linguística Aplicada, Campinas, v. 33, p. 59-70, 1999.

KALLFELL, Guido. ¿Cómo hablan los paraguayos con do s lenguas? Gramática del jopara, 2016. Tese, Westfälischen Wilhelms-Universität zu Münster, Münster, 2016.

LUSTIG, Wolf. Literatura Paraguaya en Guaraní. América sin nombre, p. 54-61, 2002. Disponível em: http://www.cervantesvirtual.com/nd/ark:/59851/bmc4f3r3. Acesso em: 4 out. 2019.

MÉNDEZ-FAITH, Teresa. Breve diccionario de la literatura paraguaya. Alicante: Biblioteca Virtual Miguel de Cervante, 2001.

MORÍNIGO, José Nicolás. La transición circular. Novapolis, p. 3-20, 2002. 
PEIRÓ, José Vicente. El robinsonismo de la narrativa paraguaya. In: BAY, Carmen Alemany; MATAIX, Remedios; ROVIRA, José Carlos. La isla posible. Alicante: Biblioteca Virtual Miguel de Cervantes, 2001. Disponível em: http://www.cervantesvirtual.com/obra/la-islaposible--0/. Acesso em: 4 out 2019.

POTTHAST, Barbara. La Mujer en la Historia del Paraguay. In: TELESCA, Ignacio. Historia del Paraguay. 3. ed. Asunción: Santillana, 2011. Cap. XIII, p. 317-335.

RABADÁN, Rosa. Equivalencia y traducción: problemática de la equivalencia traslémica inglés-españo. León: Universidad de León, 1991.

SUÁREZ, Victorio V. Proceso de la Literatura Paraguaya. 4. ed. Asunción: Fondec, 2015.

THUN, Harald. A dos mil la uva, a mil la limón. Historia, función y extensión de los artículos definidos del castellano en el guaraní jesuítico y paraguayo. In: SYMEONIDIS, O. W. D. H. Guaraní y Mawetí-Tupí-Guaraní. Berlím: Lit Verlag, 2006. p. 357-414.

THUN, Harald; CERNO, Leonardo; OBERMEIER, Franz. Guaranihape tecocue - Lo que pasó en la guerra (1704 - 1705). Kiel: Westensee Verlag, 2015.

* Maria Liz BENITEZ ALMEIDA - Doutoranda em Letras pela Universidade Federal do Rio Grande do Sul (UFRGS). Mestre em Comunicação (2017) ela Universidade Federal de Santa Maria (UFSM). Mestre em Comunicación para el Desarrollo con Énfasis en Periodismo (2016) pela Universidad Nacional del Este (UNE), Paraguai. Especialista em Didática do Ensino Superior (2010) pela Universidad Americana Sede Alto Parana Ciudad del Leste, Paraguai. Graduada em Letras Espanhol (2015) pela Universidade Federal de Santa Catarina. Graduada em Ingeniería en Marketing (2009) pela Universidad Americana del Paraguay, Paraguai. Porto Alegre, Rio Grande do Sul, Brasil.

Currículo acadêmico: http://lattes.cnpq.br/6242965599581186

ORCID: https://orcid.org/0000-0002-8397-2045

E-mail: lizbet3006@hotmail.com

\footnotetext{
${ }^{1}$ Nosso objetivo principal, nesta tradução comentada, não foi o de problematizar a escassez de estudos literários sobre a obra do autor, nem a sua invisibilidade no sistema literário latino-americano. Contudo, ao trazê-la à tona, buscamos apresentar as dificuldades de analisar de forma mais aprofundada suas obras.

${ }^{2}$ Harald Thun (2006), em estudo diacrônico, analisa as primeiras incursões dos artigos definidos no guarani e explica as novas funções que vão adquirindo na língua. No guarani contemporâneo, são utilizados o artigo feminino singular e masculino plural, no entanto, elide-se o "s" final. Servem tanto para assinalar indivíduos, pluralidade ou coletivos. A forma lo é possível encontrar em sintagmas como "lo mitã"/os moços. O la adquire funções de topicalizador e valorizador. Esses novos usos retornam ao espanhol paraguaio como empréstimo reversivo com os novos usos do guarani.
} 